\title{
Self-regulation in health care professions comes under scrutiny
}

Cite as: CMAJ 2019 August 19;191:E926-7. doi: 10.1503/cmaj.109-5790

Posted on cmajnews.com on July 30, 2019.

A $\mathrm{n}$ inquiry into the regulation of British Columbia's dentists may lead to an overhaul of health care regulation across the province - and could be a sign of what's to come across the country. The resulting report suggested that self-regulating professions too often neglect their central purpose public safety - and that a new regulatory structure should be put in place. Public feedback on the recommendations closed in June, and a government committee is expected to propose regulatory reforms later this year.

In 2018, BC's health minister, Adrian Dix, asked Harry Cayton, a regulatory expert in the United Kingdom, to look into problems with the administration and operation of the College of Dental Surgeons of British Columbia, which regulates dentists, certified dental assistants and dental therapists. He also invited Cayton to reflect on whether the Health Professions Act, the law that sets out how health professionals in the province can self-govern, needed changes.

The first part of Cayton's report described a dental regulator in disarray. The board didn't trust its registrar to take care of personnel records, for example, so the records were removed and stored offsite. The board held secret meetings and would not let the board secretary take minutes. These problems stemmed, in part, "from the belief by many dentists that they 'own' the College, that the Board therefore embodies the College and that the staff are merely functionaries whose role is to do the bidding of the Board," wrote Cayton.

Like many other health professionals, dentists regulate themselves. Selfregulation has been common in health care in Canada for more than a century, but it is a privilege granted by provincial governments. By statute, governments let certain professionals - including doctors, nurses, lawyers and teachers - make decisions about matters such as entry requirements, professional standards and appropriate discipline. Some professions are not granted this right.

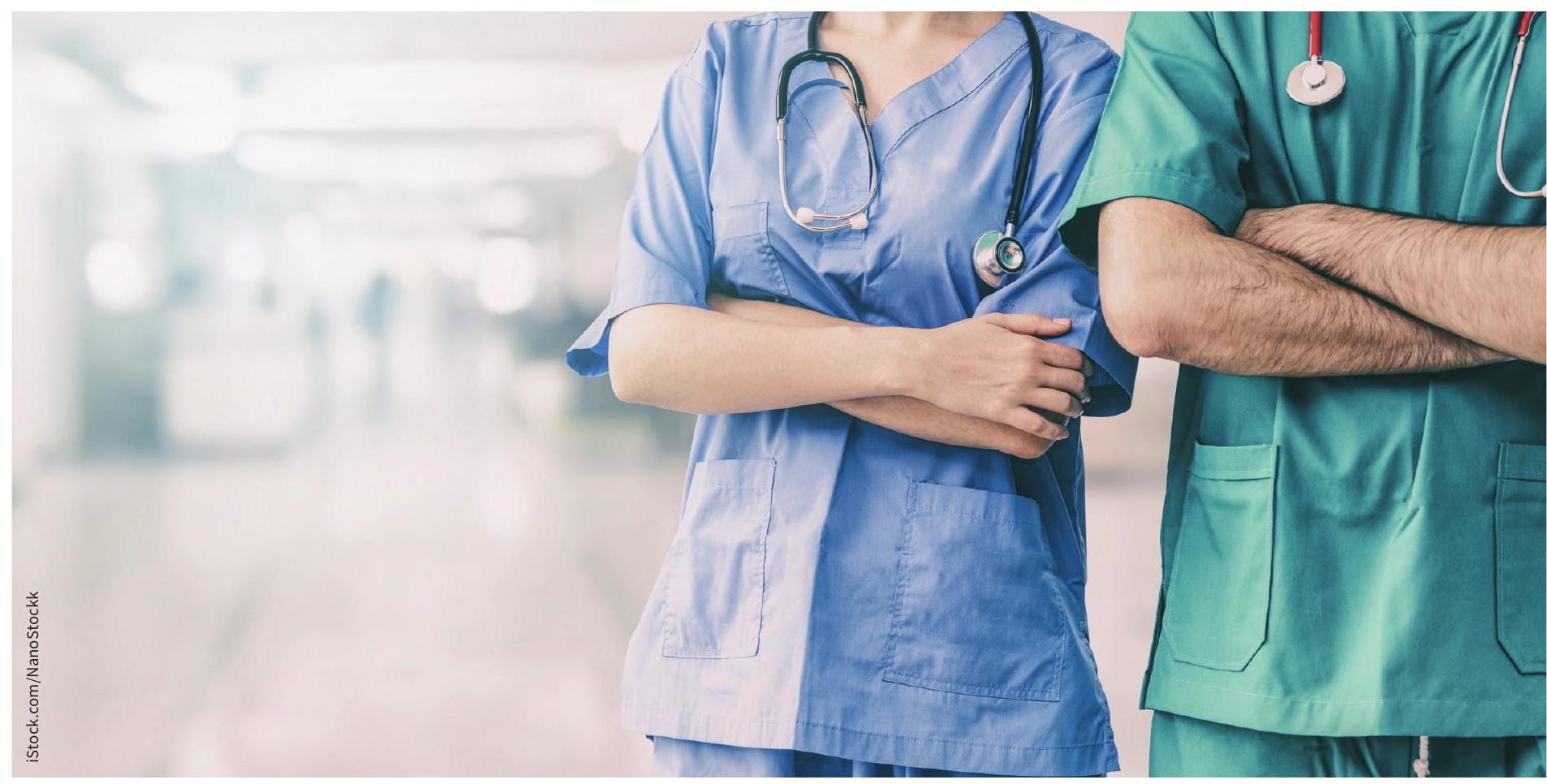

Critics of self-regulation in health care say it puts the goals of the profession ahead of the safety of patients. 
But there has been a strong worldwide trend in recent years to move away from self-regulation, said Rebecca Durcan, a lawyer at Steinecke Maciura LeBlanc in Toronto, who practises exclusively in the area of professional regulation. "This, to me, is a real response to public lack of confidence," she said. "The experiment has not worked."

In his report, Cayton called for sweeping changes across all self-regulating health care professions. Above all, he stated, regulators have to prioritize the safety of patients. Health professionals too often see a college as a means to further the goals of the profession rather than the safety of patients. "A concern for the well-being of dentists rather than a single-minded focus on patient safety and public protection is still a part of College culture," he wrote.

For starters, Cayton wants the boards of health care regulators to be more transparent and to have more representation from outside their professions. According to Durcan, adding lay people to boards is a growing trend. The UK's General Medical Council, for example, now has $50 \%$ outside representation.

Cayton also wants to do away with elected boards and move to appointments, another big trend. Elections send the wrong message, said Durcan. "You shouldn't be there because you are the most popular doctor," she said. "You shouldn't have a constituency." Cayton also recommended that boards get smaller, with no more than 12 members.

In $\mathrm{BC}$, there are 21 health care colleges; the smallest has only 78 registrants. Some of them should amalgamate, recommended Cayton.

According to Cayton, amendments here and there within the Health Professions Act will not be enough to fix the problems. "A complete overhaul of the way health professional regulation is conceived and delivered is required," he concluded. This should include a new oversight body to essentially regulate the regulators, and a new registration and adjudication body to manage complaints and levy penalties.

Durcan predicts these sorts of changes will soon happen across Canada. "The rest of the western regulatory world has already signed on to this."

Health care colleges in other provinces have been paying attention to Cayton's report. The Saskatchewan College of Pharmacy Professionals stated that the report "will have implications for all regulators in Canada." The College of Midwives of Ontario said it "supports the call for governance reform as outlined in the Cayton report." Even regulatory bodies outside health care have weighed in. For instance, the Human Resources Professionals Association, which regulates human resources workers in Ontario, noted that the "world of professional regulation is buzzing" about the Cayton report and "the landscape of professional regulation is likely to change in significant ways."

Alison Motluk, Toronto, Ont. 